\title{
MiR-30a-5p confers cisplatin resistance by regulating IGF1R expression in melanoma cells
}

Yuxia Li', Jie Zhang ${ }^{2}$, Yajing Liu', Bingyue Zhang ${ }^{1}$, Fubo Zhong ${ }^{1}$, Shubin Wang ${ }^{2^{*}}$ and Zhengyu Fang ${ }^{1^{*}}$

\begin{abstract}
Background: Melanoma is notoriously resistant to all current modalities of cancer therapies including chemotherapy. In recent years, microRNAs (miRNAs) have emerged as molecular regulators in the development and progression of melanoma. However, the relationship between microRNA and chemo-resistance of melanoma is little known. In present study, we aimed to investigate the miRNAs related to cisplatin-resistance in melanoma cells.

Methods: After cisplatin (DDP) resistant melanoma cells (M8/DDP and SK-Mel-19/DDP) were established in-vitro, high-throughput screening of differentially expressed miRNAs between resistant cells and parental cells were performed.

Results: It was found that a cancer-related miRNA, miR-30a-5p, was highly over-expressed in resistant cells. Transfection of miR-30a-5p mimic or inhibitor could alter the sensitivity of melanoma cells to cisplatin. Next, we showed that Insulin Like Growth Factor 1 Receptor (IGF1R) gene turned out to be a direct target of miR-30a-5p. Knockdown of IGF1R in melanoma cells could not only reduce the sensitivity to cisplatin but also lead to cell cycle arrest by regulating phosphorylation of Serine-Threonine Protein Kinase (P-AKT (Ser473)) and Tumor Protein P53 (P53).

Conclusion: Taken together, our study demonstrated that miR-30a-5p could influence chemo-resistance by targeting IGF1R gene in melanoma cells, which might provide a potential target for the therapy of chemo-resistant melanoma cells.
\end{abstract}

Keywords: Melanoma, Cisplatin, miR-30a-5p, IGF1R, Chemo-resistance

\section{Background}

Melanoma is developed from melanocytes, and is the world's most aggressive skin cancer [1]. Although highly effective new treatment strategies have been gradually used, chemotherapy is still a major treatment for melanoma [2]. Cisplatin is one of the most commonly used chemotherapeutic agents for melanoma. However, the lack of response due to cisplatin resistance has been a main problem that affects the outcome of melanoma therapy. Thus, adjuvant therapy to enhance cisplatin

\footnotetext{
*Correspondence: wangshubin2013@163.com; fangzy796@163.com 2Department of Medical Oncology, Peking University Shenzhen Hospital, No. 1120 Lianhua Road, Futian District, Shenzhen, Guangdong Province, China ${ }^{1}$ Biomedical Research Institute, Shenzhen Peking University-The Hong Kong University of Science and Technology Medical Center, No. 1120 Lianhua Road, Futian District, Shenzhen, Guangdong province, China
}

efficiency has become an important chemotherapeutic strategy.

MiRNA is a kind of 20-24 nt non-coding single strand RNA that has been shown to extensively involve in the translational inhibition which is relevant to several physiological and pathological processes. The mechanism of their action is mainly based on the incomplete matching between the seed region of the 5'end of the 21-23 nt sequence and the partial complementary sequence of the $3^{\prime}$ untranslated region(3'-UTR) of target mRNAs [3-5]. Recent studies have suggested that chemo-resistance of cancer cells might be modulated via the changes of miRNA levels [6-11]. For instance, miR-92b is significantly up-regulated in lung cancer cells and knockdown of miR-92b inhibits cell growth and sensitizes A549/DDP cells to DDP by targeting phosphatase and tensin homolog (PTEN) [12]. 
MiR-26b is prominently down-regulated in DDP-resistant nasopharyngeal carcinoma cells and induces cisplatin resistance by repressing Jagged 1(JAG1) [13]. In Hep-2 laryngeal cancer stem cells, osteosarcoma cells and ovarian cancer cells, miR-125a, miR-497 and miR-199a are able to reverse cisplatin resistance respectively [14-16].

Till now, there is few report about the role of miRNAs in the chemo-resistance of melanoma cells. In present study, we constructed two cisplatin resistant melanoma cell lines and screened miRNAs that related to cisplatin resistance. Here we reported that miR-30a-5p was overexpressed in cisplatin resistant melanoma cells and could influence the activity of PI3K/AKT and the protein level of P53 by targeting IGF1R gene. These results may provide new insights into the molecular mechanisms of cisplatin resistance in melanoma cells and novel therapeutic targets to cure chemo-resistant melanoma.

\section{Methods}

\section{Cell culture}

Human melanoma cancer cells (M8, M8/DDP, SK-Mel19 and SK-Mel-19/DDP) and HEK293T cells were obtained from Jennio Biotech. (Jennio, China). All cells were cultured in Dulbecco Modified Eagle Medium (DMEM, Gibco, USA) supplemented with $10 \%$ fetal bovine serum (FBS, Gibco, USA), $100 \mathrm{IU} / \mathrm{ml}$ penicillin (Gibco, USA), and $100 \mu \mathrm{g} / \mathrm{ml}$ streptomycin (Gibco, USA) in a humidified atmosphere containing $5 \% \mathrm{CO}_{2}$ at $37{ }^{\circ} \mathrm{C}$, and subcultured every 3 days at $10-30 \%$ confluence. To establish cisplatin-resistant M8/DDP and SKMel-19/DDP cells, M8 and SK-Mel-19 cells were first treated with $0.52 \mu \mathrm{mol} / \mathrm{L}(\mu \mathrm{M})$ of cisplatin (Hansoh, China), and then were treated with increased concentrations of cisplatin in a stepwise manner during each passage. To maintain the drug-resistance phenotype, cisplatin (with the final concentration of $33.4 \mu \mathrm{M}$ ) was added to the culture media for M8/DDP and SK-Mel-19/DDP cells.

\section{Drug sensitivity assay}

Human melanoma cancer cells M8, M8/DDP, SK-Mel19 and SK-Mel-19/DDP were plated in 6-well plates $\left(3 \times 10^{5}\right.$ cells/well $)$ and 100 pmol of the miR-30a-5p mimic or mimic control were transfected into M8 and SK-Mel-19 cells, while 100 pmol of the miR-30a-5p inhibitor or inhibitor control were transfected into the M8/DDP and SK-Mel-19/DDP, using Lipofectamine2000 (Invitrogen, USA) according to the manufacturer's protocol. $24 \mathrm{~h}$ after medium changed, the cells were seeded in 96-well plates (M8 and M8/DDP were $4 \times 10^{3}$ cells/well; SK-Mel-19 and SK-Mel-19/ DDP were $5 \times 10^{3}$ cells/well) for the following experiment. After cell adhesion, cisplatin was added at a final concentration of 4.18 , $8.35,16.7,33.4,66.8 \mu \mathrm{M}$ to cells. $72 \mathrm{~h}$ after the addition of the drug, cell viability was assessed by 3-(4,5- dimethylthiazol-2-yl)-5-(3-carboxymethoxyphenyl)-2-(4sulfophenyl)-2H-tetrazolium, inner salt (MTS, Promega, USA) assay according to the manufacturer's protocol. The absorbance at $490 \mathrm{~nm}$ (A490) of each well was read on iMark Microplate Absorbance Reader (Bio-Rad, USA).

\section{Real-time quantitative PCR}

Total RNA was isolated from cells at the logarithmic phase using Trizol (Sigma, USA) according to the manufacturer's protocol. First-strand cDNA was synthesised using GoScript ${ }^{\mathrm{TM}}$ Reverse Transcription System Kit (Promega, USA). Real-time PCR was performed with GoTaq qPCR Master Mix (Promega, USA) using a C1000 Thermal Cycler apparatus (Bio-Rad) in $20 \mu$ reaction volume according to manufacturer's protocols. The procedure was as follows: $95{ }^{\circ} \mathrm{C}-3 \mathrm{~min} ; 39 \times\left(95{ }^{\circ} \mathrm{C}-15 \mathrm{~s}, 60{ }^{\circ} \mathrm{C}\right.$ $60 \mathrm{~s}, 72{ }^{\circ} \mathrm{C}-30 \mathrm{~s}$, for mRNA; $95{ }^{\circ} \mathrm{C}-15 \mathrm{~s}, 60{ }^{\circ} \mathrm{C}-60 \mathrm{~s}$ for miRNA); $95{ }^{\circ} \mathrm{C}-10 \mathrm{~s}$, followed by a melt curve analysis $\left(60{ }^{\circ} \mathrm{C}\right.$ to $95{ }^{\circ} \mathrm{C}$, increment $0.5{ }^{\circ} \mathrm{C}$ for $20 \mathrm{~s}$ ) to confirm specificity of the PCR primers. Threshold cycle (Ct)values for mRNA and miRNA species were normalized to housekeeping genes: GADPH for mRNAs and U6 for mature miRNAs (Primers were listed in Table 1). The fold change was calculated using the $2^{-\Delta \Delta C t}$ Method.

\section{Western blot analysis}

Cells were lysed in SDS lysis buffer (Beyotime, China) supplemented with protease inhibitor cocktail (Takara, China). Total protein was quantified by BCA Protein Assay Kit (Beyotime, China), and proteins $(10 \mu \mathrm{g} /$ per lane) were separated by SDS-PAGE and transferred onto a polyvinylidene fluoride (PVDF) membrane (Pall, USA). The membranes were blocked in bovine serum albumin (BSA) $(3 \% w / v$ in $\mathrm{PBS}+0.1 \% \mathrm{w} / \mathrm{v}$ in Tween 20) for $30 \mathrm{~min}$ at room temperature and incubated with diluted antibodies at $4{ }^{\circ} \mathrm{C}$ overnight. Proteins were detected by enhanced chemiluminescence system (Pierce, USA) according to the manufacturer's instructions. Data were normalized to GAPDH.

\section{Plasmid construction and lentiviral infection}

To knock down miR-30a-5p expression, TuD-miR-30a$5 \mathrm{p}$ was constructed based on the Tough Decoy (TuD) design [17]. Oligonucleotides of the Tough Decoy RNA were annealed and cloned into BamHI and MluI site of lentiviral vector pLent-U6-GFP-puro (ViGene, China), resulting in TuD-miR-30a-5p being driven by polymerase III promoter U6. Lentivirus was produced by transfecting HEK293T cells with each lentiviral construct together with the packaging vectors psPAX2 and pMD2.G (ViGene, China) using Lipofectamine-2000 (Introvigen, USA) according to the instructions of the manufacturer. The supernatant was collected $72 \mathrm{~h}$ after 
Table 1 Primers list

\begin{tabular}{|c|c|}
\hline Primer name & Sequence ( $5^{\prime}$ to $\left.3^{\prime}\right)$ \\
\hline has-miR-10b-5p-F & GCCATTACCCTGTAGAACCG \\
\hline has-miR-10b-5p-RT & $\begin{array}{l}\text { GTCGTATCCAGTGCGTGTCGTGGAGTC } \\
\text { GGCAATTGCACTGGATACGACCACAAA }\end{array}$ \\
\hline has-miR-1246-F & CGGGAGAATGGATITTGG \\
\hline has-miR-1246-RT & $\begin{array}{l}\text { GTCGTATCCAGTGCGTGTCGTGGAGTCG } \\
\text { GCAATTGCACTGGATACGACCCTGCT }\end{array}$ \\
\hline has-miR-138-5p-F & GCGAAGCTGGTGTTGTGAA \\
\hline has-miR-138-5p-RT & $\begin{array}{l}\text { GTCGTATCCAGTGCGTGTCGTGGAGTCG } \\
\text { GCAATTGCACTGGATACGACCGGCCT }\end{array}$ \\
\hline has-miR-146a-5p-F & CGGCGGCTGAGAACTGAAT \\
\hline $\begin{array}{l}\text { has-miR-146a-5p- } \\
\text { RT }\end{array}$ & $\begin{array}{l}\text { GTCGTATCCAGTGCAGGGTCCGAGGTA } \\
\text { TTCGCACTGGATACGACAACCCA }\end{array}$ \\
\hline has-miR152-3p-F & CGGCTCAGTGCATGACAGA \\
\hline has-miR152-3p-RT & $\begin{array}{l}\text { GTCGTATCCAGTGCGTGTCGTGGAGTCG } \\
\text { GCAATTGCACTGGATACGACCCAAGT }\end{array}$ \\
\hline has-miR-15a-3p-F & CCGTCCAGGCCATATTGTG \\
\hline has-miR-15a-3p-RT & $\begin{array}{l}\text { GTCGTATCCAGTGCAGGGTCCGAGGTAT } \\
\text { TCGCACTGGATACGACTGAGGC }\end{array}$ \\
\hline has-miR-181a-3p-F & CAGCACCATCGACCGTTGA \\
\hline $\begin{array}{l}\text { has-miR-181a-3p- } \\
\text { RT }\end{array}$ & $\begin{array}{l}\text { GTCGTATCCAGTGCGTGTCGTGGAGTCG } \\
\text { GCAATTGCACTGGATACGACGGTACA }\end{array}$ \\
\hline has-miR-181a-5p-F & GACGCAACATTCAACGCTG \\
\hline $\begin{array}{l}\text { has-miR-181a-5p- } \\
\text { RT }\end{array}$ & $\begin{array}{l}\text { GTCGTATCCAGTGCAGGGTCCGAGGTAT } \\
\text { TCGCACTGGATACGACACTCAC }\end{array}$ \\
\hline has-miR-182-5p-F & CGGATTTGGCAATGGTAGA \\
\hline has-miR-182-5p-RT & $\begin{array}{l}\text { GTCGTATCCAGTGCGTGTCGTGGAGTCG } \\
\text { GCAATTGCACTGGATACGACAGTGTG }\end{array}$ \\
\hline has-miR-193a-5p-F & ATCTATGGGTCTITGCGGG \\
\hline $\begin{array}{l}\text { has-miR-193a-5p- } \\
\text { RT }\end{array}$ & $\begin{array}{l}\text { GTCGTATCCAGTGCGTGTCGTGGAGTCG } \\
\text { GCAATTGCACTGGATACGACTCATCT }\end{array}$ \\
\hline has-miR-210-3p-F & CAGTGGCTGTGCGTGTGAC \\
\hline has-miR-210-3p-RT & $\begin{array}{l}\text { GTCGTATCCAGTGCGTGTCGTGGAGTCG } \\
\text { GCAATTGCACTGGATACGACTCAGCC }\end{array}$ \\
\hline has-miR-21-3p-F & ACGGCACCAACACCAGTCG \\
\hline has-miR-21-3p-RT & $\begin{array}{l}\text { GTCGTATCCAGTGCAGGGTCCGAGGTAT } \\
\text { TCGCACTGGATACGACACAGCC }\end{array}$ \\
\hline has-miR-301a-3p-F & AGGCGGCAGTGCAATAGTA \\
\hline $\begin{array}{l}\text { has-miR-301a-3p- } \\
\text { RT }\end{array}$ & $\begin{array}{l}\text { GTCGTATCCAGTGCGTGTCGTGGAGTCG } \\
\text { GCAATTGCACTGGATACGACGCTITG }\end{array}$ \\
\hline has-miR-30a-5p-F & TGCCGTGTAAACATCCTCG \\
\hline has-miR-30a-5p-RT & $\begin{array}{l}\text { GTCGTATCCAGTGCGTGTCGTGGAGTCG } \\
\text { GCAATTGCACTGGATACGACCTTCCA }\end{array}$ \\
\hline has-miR-449b-3p-F & GCGTCAGCCACAACTACCC \\
\hline $\begin{array}{l}\text { has-miR-449b-3p- } \\
\text { RT }\end{array}$ & $\begin{array}{l}\text { GTCGTATCCAGTGCGTGTCGTGGAGTCGGC } \\
\text { AATTGCACTGGATACGACAGTGGC }\end{array}$ \\
\hline has-miR-454-5p-F & CAGCGGCACCCTATCAATA \\
\hline has-miR-454-5p-RT & $\begin{array}{l}\text { GTCGTATCCAGTGCAGGGTCCGAGGTATTCG } \\
\text { CACTGGATACGACGCAGAG }\end{array}$ \\
\hline has-miR-4701-3p-F & CCAGATGGGTGATGGGTGT \\
\hline
\end{tabular}

Table 1 Primers list (Continued)

\begin{tabular}{|c|c|}
\hline Primer name & Sequence ( $5^{\prime}$ to $\left.3^{\prime}\right)$ \\
\hline $\begin{array}{l}\text { has-miR-4701-3p- } \\
\text { RT }\end{array}$ & $\begin{array}{l}\text { GTCGTATCCAGTGCAGGGTCCGAGG } \\
\text { TATTCGCACTGGATACGACACACCA }\end{array}$ \\
\hline URP-1 & GTGTCGTGGAGTCGGCAA \\
\hline URP-2 & CGCAGGGTCCGAGGTATTC \\
\hline U6-F & CTCGCTTCGGCAGCACA \\
\hline U6-R & AACGCTTCACGAATTTGCGT \\
\hline IGF1R-F & GGCTGGGGCTCTTGTTTACC \\
\hline IGF1R-R & GCCTCTCTCGAGTTCGCC \\
\hline GAPDH-F & TCCAAAATCAAGTGGGGCGA \\
\hline GAPDH-R & TGATGACCCTITTGGCTCCC \\
\hline TuD-miR-30a-5p-R & $\begin{array}{l}\text { CGCGAAAAAAGACGGCGCTAGGATCAT } \\
\text { CTTGTGTAAACATCAGATCTCGACTGGA } \\
\text { AGGTTGTATTCTGTGACCAGAATACTTG } \\
\text { TGTAAACATCAGATCTCGACTGGAAGGT } \\
\text { TGATGATCCTAGCGCCGTCG }\end{array}$ \\
\hline IGF1R-wt-F & $\begin{array}{l}\text { AATTCTAGCGATCGCTCGAG } \\
\text { TCGCACTCGTCAGTTGTCAGTT }\end{array}$ \\
\hline IGF1R-wt-R & $\begin{array}{l}\text { ATITTATTGCGGCCAGCGGCCGCA } \\
\text { TCCTIITTGGCATATTGTAAAGC }\end{array}$ \\
\hline IGF1R-mut A-F & $\begin{array}{l}\text { CGAAGATCTGCAAATGTAGAACTA } \\
\text { ATTAAATGTITCATTGCATTT }\end{array}$ \\
\hline IGF1R-mut A-R & $\begin{array}{l}\text { ACATTTGCAGATCTTCGTCAACTGA } \\
\text { CTACCCG }\end{array}$ \\
\hline IGF1R-mut B-F & $\begin{array}{l}\text { GACACCACAAATGTAGCTAGCTTTACA } \\
\text { ATATGCCAAAAA }\end{array}$ \\
\hline IGF1R-mut B-R & $\begin{array}{l}\text { GCTACATTTGTGGTGTCCTAAAAAAAAA } \\
\text { AAAAAAAAA }\end{array}$ \\
\hline
\end{tabular}

transfection and was centrifuged (4000 g for $5 \mathrm{~min}$ at room temperature) to remove cell debris; the supernatant was used for M8/DDP and SK-Mel-19/DDP cells infection. The infected cells were then selected by supplementing the culture medium with $6 \mu \mathrm{g} / \mathrm{ml}$ of puromycin $48 \mathrm{~h}$ after infection. The efficiency of the inhibition of miRNAs was confirmed by real-time PCR analysis.

\section{Dual luciferase reporter assays}

Based on the miRNA databases (microRNA.org, miRDB and TargetScan databases), IGF1R is a predicted target of miR-30a-5p. Hence, we cloned IGF1R 3'-UTR fragment containing the predicted site (5'-GTTTACA-3' and 5'-TGTTTAC-3') or the mutant sequence (5'CAAATGT-3' and 5' -ACAAATG-3') into psiCHECK ${ }^{\mathrm{Tm}}-2$ luciferase reporter vector (Promega, USA) (Primers were listed in Table 1). For luciferase assay, the reporter plasmid was co-transfected with miR-30a-5p mimic or mimic control in HEK293T cells. After $48 \mathrm{~h}$, cells were lysed and luciferase expression was measured using the Dual-luciferase assay system (Promega, USA) following the manufacturer's protocol. The renilla luciferase (Rluc) was normalized by the firefly luciferase (Luc). 


\section{Data analysis}

GraphPad Prism software (La Jolla, CA) was used to plot the curves and statistical analysis. Data were presented as mean \pm SD from at least three independent experiments. Statistical analysis was performed by Student's $t$ test. $p$ values of $<0.05\left(^{*}\right),<0.01(* *)$, and $<0.001(* * *)$ were considered significant.

\section{Results}

MiR-30a-5p is highly expressed in cisplatin-resistant melanoma cells

Two cisplatin-resistant cell lines M8/DDP and SK-Mel19/DDP were induced by continuous exposure to cisplatin after 5 months for more than 50 cell passages. The cell lines were used for experiments after culturing in drugfree medium for another 2 months. We then tested the half maximal inhibitory concentration $\left(\mathrm{IC}_{50}\right)$ and drug resistance indices (RI) of the resistant cells as well as their parental cells by MTS assay. In Fig. $1 \mathrm{a}$ and b, the $\mathrm{IC}_{50}$ of M8 cells was $3.97 \mu \mathrm{M}$, the $\mathrm{IC}_{50}$ of M8/DDP cells was $21.23 \mu \mathrm{M}$, the resistance index was 5.3 ; the $\mathrm{IC}_{50}$ of SKMel-19 cells was $10.16 \mu \mathrm{M}$, the $\mathrm{IC}_{50}$ of SK-Mel-19/DDP cells was $31.93 \mu \mathrm{M}$, and its resistance index was 3.1. The results indicated that the resistant lines were established successfully. Since the drug-resistant cells differed significantly from their parental cells at cisplatin concentrations of $4.18 \mu \mathrm{M}, 8.35 \mu \mathrm{M}, 16.7 \mu \mathrm{M}, 33.4 \mu \mathrm{M}$, and $66.8 \mu \mathrm{M}$, these five concentrations were selected for follow-up experiments.

We used microRNA microarray analysis to screen the differential expressed miRNAs ( $\geq 2.0$ fold or $\leq 0.5$ fold) between the resistant cells and their parental cells, and 21 miRNAs were verified by real-time PCR and listed in Table 2. Among them, a cancer-related miRNA, miR$30 a-5 p$, was found to be markedly up-regulated in both M8/DDP and SK-Mel-19/DDP cells. This difference in expression of miR-30a-5p was also validated by real-time PCR analysis (Fig. 1c), the difference multiples of miR$30 \mathrm{a}-5 \mathrm{p}$ were 35.37 and 5.65 .
MiR-30a-5p affects the resistance of melanoma cells to cisplatin

To explore the potential roles of miR-30a-5p in the cisplatin-resistance of melanoma cells, in-vitro studies using miR-30a-5p mimics and inhibitors were performed. As shown in Fig. 2a, the $\mathrm{IC}_{50}$ of $\mathrm{M} 8$ cells increased when transfected with miR-30a-5p mimic, which indicated their resistance to cisplatin was enhanced. Similar results were obtained in SK-Mel-19 cells. On the other hand, the $\mathrm{IC}_{50}$ of M8/DDP cells was markedly reduced after transfected with miR-30a-5p inhibitor, which could also be repeated in the SK-Mel-19/DDP cells.

Transfection into a cell can be transient or stable. To further study the relationship between miR-30a-5p and cisplatin resistance in melanoma, we constructed a Tough Decoy (TuD) vector expressing a miR-30a-5p$\mathrm{TuD}$ that could stably suppress the expression of miR30a-5p in M8/DDP and SK-Mel-19/DDP cells (Fig. 2b). Knockdown efficiency of the stable transfection was validated by the real-time PCR analysis (Fig. 2c), the transfection of TuD-miR-30a-5p reduced the expression of miR-30a-5p by more than 40\% in M8/DDP and SK-Mel19/DDP cells. As shown in Fig. 2d, the $\mathrm{IC}_{50}$ of M8/DDP and SK-Mel-19/DDP cells decreased significantly after stably transfected with TuD-miR-30a-5p. In both transient transfection and stable transfection approaches, the sensitivity of the melanoma cells to cisplatin was influenced by the change of miR-30a-5p expression. These provide the evidence of the association between miR$30 \mathrm{a}-5 \mathrm{p}$ and cisplatin-resistance of the melanoma cells.

\section{The insulin like growth factor 1 receptor (IGF1R) is a direct target of miR-30a-5p}

Identification of miRNA-regulated gene targets is a necessary step to understand miRNA functions. First, we used the online tools (microRNA.org, miRDB and TargetScan databases) to screen the potential target genes of miR30a-5p. Among the genes obtained from screening results, we noticed that a cancer-related gene, IGF1R, might be a
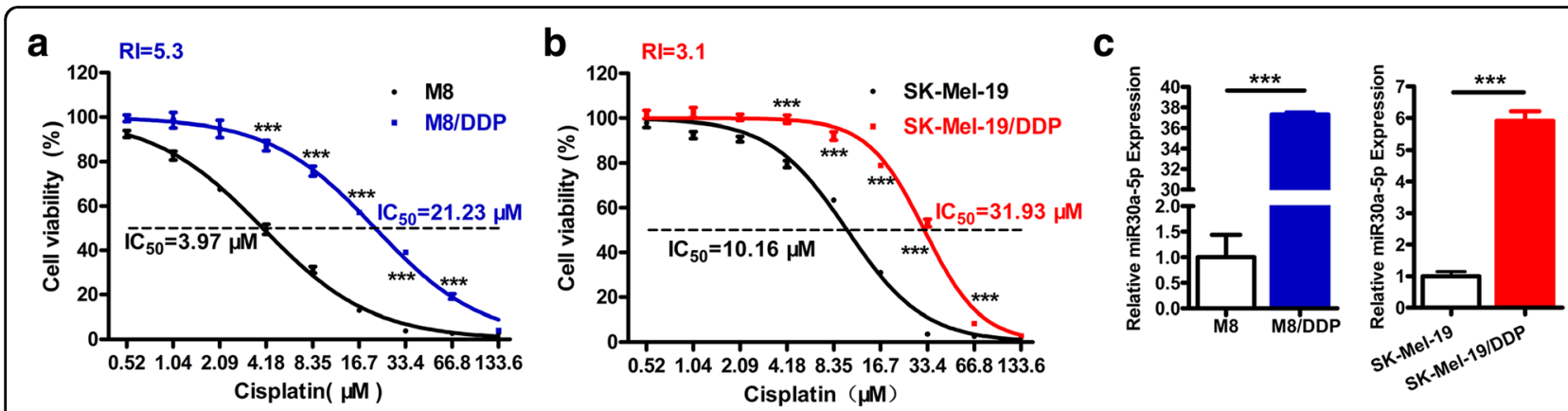

Fig. 1 MiR-30a-5p is highly expressed in cisplatin-resistant melanoma cells. a, b M8, M8/DDP, SK-Mel-19 and SK-Mel-19/DDP cells were treated with indicated concentrations of cisplatin for $72 \mathrm{~h}$ and then were subjected to MTS assay. c The mRNA expression level of miR-30a-5p in M8, M8/ DDP, SK-Mel-19 and SK-Mel-19/DDP cells was detected by real-time PCR analysis 
Table 2 Differential Expressed miRNAs between resistant cells and the parental cells

\begin{tabular}{|c|c|c|c|c|c|}
\hline \multirow{2}{*}{$\begin{array}{l}\text { miRBase } \\
\text { accession No. }\end{array}$} & \multirow[t]{2}{*}{ miRNA } & \multicolumn{2}{|c|}{ M8/DDP vs M8 } & \multicolumn{2}{|c|}{ SK-Mel-19/DDP vs SK-Mel-19 } \\
\hline & & Change & $P$-value & Change & $P$-value \\
\hline MIMAT0000254 & hsa-miR-10b-5p & 0.62 & 0.04 & 0.86 & 0.09 \\
\hline MIMAT0005898 & hsa-miR-1246 & 0.35 & 0.04 & 1.42 & 0.25 \\
\hline MIMAT0000430 & hsa-miR-138-5p & 1.33 & 0.18 & 3.00 & 0.83 \\
\hline MIMAT0000449 & hsa-miR-146a-5p & 0.78 & 0.04 & 1.70 & 0.04 \\
\hline MIMAT0000438 & hsa-miR-152-3p & 0.39 & 0.02 & 3.45 & 0.50 \\
\hline MIMAT0004488 & hsa-miR-15a-3p & 1.17 & 0.13 & 0.59 & 0.14 \\
\hline MIMAT0000270 & hsa-miR-181a-3p & 1.57 & 0.03 & 1.70 & 0.38 \\
\hline MIMAT0000256 & hsa-miR-181a-5p & 2.19 & 0.06 & 2.50 & 0.49 \\
\hline MIMAT0000259 & hsa-miR-182-5p & 0.94 & 0.03 & 1.30 & 0.07 \\
\hline MIMAT0004614 & hsa-miR-193a-5p & 0.77 & 0.07 & 0.53 & 0.05 \\
\hline MIMAT0000267 & hsa-miR-210-3p & 1.77 & 0.15 & 0.61 & 0.08 \\
\hline MIMAT0004494 & hsa-miR-21-3p & 0.35 & 0.06 & 0.64 & 0.20 \\
\hline MIMAT0000688 & hsa-miR-301a-3p & 1.35 & 0.29 & 1.12 & 0.34 \\
\hline MIMAT0000087 & hsa-miR-30a-5p & 35.37 & 0.06 & 5.65 & 0.85 \\
\hline MIMAT0009203 & hsa-miR-449b-3p & 2.43 & 0.68 & 0.95 & 0.29 \\
\hline MIMAT0003884 & hsa-miR-454-5p & 3.12 & 0.10 & 0.79 & 0.16 \\
\hline MIMAT0019799 & hsa-miR-4701-3p & 1.20 & 0.35 & 1.33 & 0.09 \\
\hline MIMAT0003304 & hsa-miR-634 & 2.83 & 0.23 & 0.80 & 0.01 \\
\hline MIMAT0027433 & hsa-miR-6766-3p & 1.07 & 0.08 & 1.09 & 0.32 \\
\hline MIMAT0027459 & hsa-miR-6779-3p & 1.75 & 0.65 & 1.09 & 0.44 \\
\hline MIMAT0027484 & hsa-miR-6792-5p & 1.59 & 0.46 & 0.76 & 0.14 \\
\hline
\end{tabular}

tentative target of miR-30a-5p whose 3'-UTR contains two putative miR-30a-5p seed sites (Fig. 3a). We noticed that the mRNA and protein levels of IGF1R in M8/DDP and SK-Mel-19/DDP were significantly lower than those in the parental cells (Fig. 3b \& c), which were contrary to the expression levels of miR-30a-5p in the two groups. In the in-vitro approaches, transfection of miR-30a-5p mimics could reduce the protein levels of IGF1R in M8 and SK-Mel-19 cells, while transfection of miR-30a-5p inhibitors could promote the expression of IGF1R in the resistant cells. At the same time, we noticed that the mRNA levels of IGF1R were less influenced by the alteration of miR-30a-5p expression (Fig. 3d and e), which suggested that miR-30a-5p could not induce the degradation of IGF1R mRNA.

To test whether the predicted miR-30a-5p target sites in the 3'-UTR of IGF1R mRNA were responsible for its regulation, we cloned IGF1R 3'-UTR wild type (wt) or 3'-UTR mutant types (mut A, mut A and mut A B) into downstream of the luciferase reporter gene. In the absence of miR-30a-5p, luciferase would be expressed, whereas in the presence of miR-30a-5p, luciferase mRNA would be degraded. As shown in Fig. 3f, when the double luciferase reporter vector containing the wild type of IGF1R 3'-UTR and miR-30a-5p mimic were co- transfected into HEK293T cells, the Renilla luciferase activities were significantly inhibited. Mutations of the IGF1R 3'-UTR binding site in region A drastically abolished ability of miR-30a-5p to regulate luciferase expression, while mutations in the region $\mathrm{B}$ partially impaired the luciferase expression. Thus, miR-30a-5p could directly bind to both region A and B on 3'-UTR of IGF1R gene.

\section{IGF1R can influence cell cycle of melanoma cells by regulating AKT activity and protein level of P53}

We next investigated whether IGF1R itself could influence cisplatin resistance in the two melanoma cell lines. We conducted small interfering RNA (siRNA)-based silencing of IGF1R and assessed its efficiency in M8 and SK-Mel-19 cells. As shown in Fig. 4a, siRNA3 was more efficient in M8 cells and siRNA2 was more efficient in SK-Mel-19 cells. After transfection these two small interfering RNA, the expression of miR-30a-5p reduced more than $40 \%$ in M8 and SK-Mel-19 cells. Then, after IGF1R was knockdown in the M8 and SK-Mel-19 cells using the appropriate siRNAs, the sensitivities of both cell lines to cisplatin were reduced (Fig. 4b).This suggested the direct correlationship between IGF1R and cisplatinresistance in melanoma cells. 
As a receptor of insulin-like growth factor, IGF1R has tyrosine kinase activity and plays a critical role in transformation events. Previous studies have shown that activation of the IGF1R signaling pathway is involved in proliferation, survival, and metastasis of cancer cells. In the present study, we noticed that the expression of phosphorylation of AKT (Ser473) was lower while the expression of P53 protein was higher in the resistant cells compared to their parental cells (Fig. 4c). We wondered whether it was associated with the alteration of IGF1R. In the subsequent in-vitro studies, we used the specific siRNA to knockdown the expression of IGF1R in M8 and SK-Mel-19 cells, and found that the phosphorylation of AKT (Ser473) was impaired while the protein levels of P53 were increased (Fig. 4d). At the same time, cell cycle arrests were detected in both cell lines (Fig. 5a). Based on the $\mathrm{IC}_{50}$ of M8 and SKMel-19 cells (Fig. 1a and b, Fig. 4b), we selected three concentrations of cisplatin(4.18 $\mu \mathrm{M}, 8.35 \mu \mathrm{M}$ and $16.7 \mu \mathrm{M})$ that cover the range of $\mathrm{IC}_{50}$ of the both cell lines for cell cycle examination. Interestingly, we found that cisplatin at concentration of $8.35 \mu \mathrm{M}$ influence the cell cycle most significantly in the both cell lines. As shown in Fig. 5a, after M8 cells were treated with cisplatin, a G2/M arrest was induced. When the IGF1R was silenced before the cisplatin treatment, the G2/M arrest was impaired. On the other hand, in case of SK-Mel-19 cells, cisplatin treatment induced cell cycle disruption. However, when the IGF1R was silenced before the cisplatin treatment, the cell cycle only varied a little after cisplatin treatment. Thus, IGF1R might play a protective role in cisplatin-mediated DNA damage through regulating cell cycle by influencing AKT/P53 pathway in melanoma cells.

\section{Discussion}

Here we identified a novel miR-30a-5p/IGF1R/AKT/P53 signaling axis that regulates melanoma cells in cisplatin resistance. Our data provide a first insight into the function of miR-30a-5p in regulating cisplatin resistance. Because resistance to cisplatin treatment is one of major causes for chemotherapy failure in treating melanoma

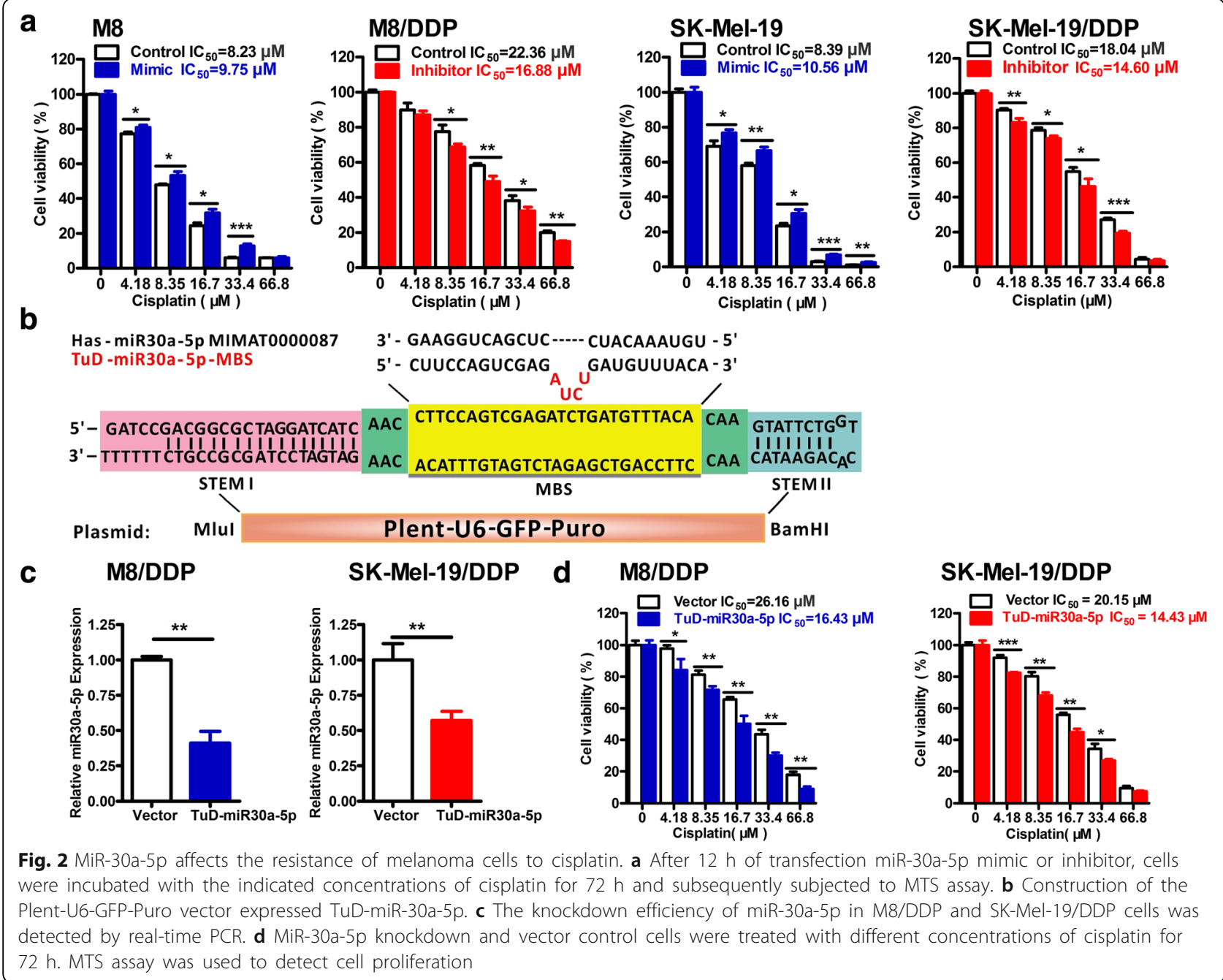




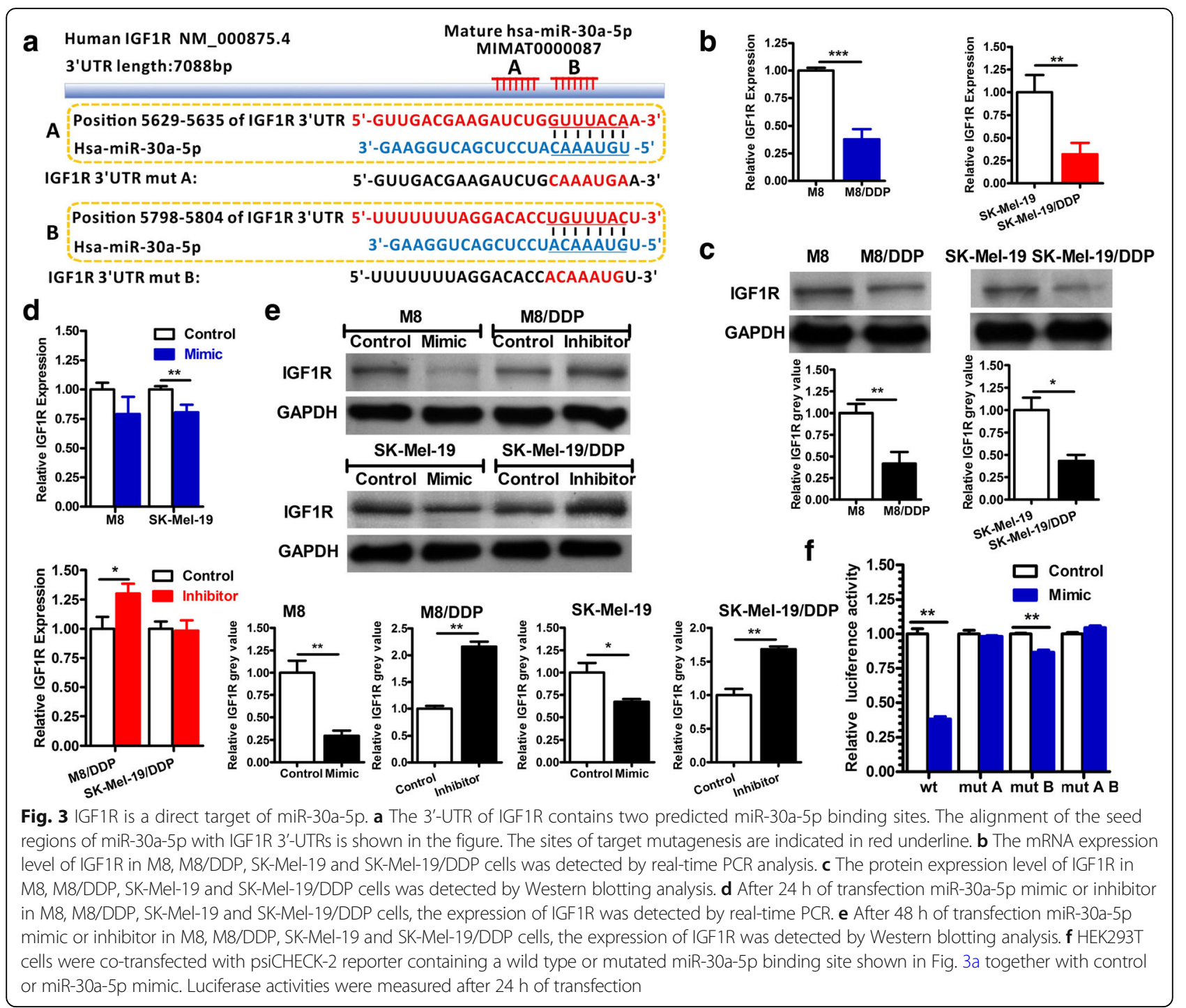

[18-20], the discovery of miR-30a-5p as a contributing factor of cisplatin resistance and the identification of the regulatory miR-30a-5p/IGF1R/AKT/P53 signaling axis would help design strategies to increase the efficacy of chemotherapeutic treatment of melanoma.

Some studies have shown that miR-30s have been found involved in the regulation of cisplatin-sensitivity of some cancers, where individual members of the miR30 family assist cancer cells in both cisplatin sensitivity and cisplatin insensitivity [21-23].In the current study, miR-30a-5p is highly expressed in M8/DDP and SK-Mel-19/DDP cells. Transfection of miR-30a-5p mimics in M8 and SK-Mel-19 cells could enhance the cisplatin-resistance of the cells, while knockdown of miR-30a-5p could impair the resistance of M8/DDP and SK-Mel-19/DDP cells to cisplatin. These findings suggested that miR-30a-5p did correlate with cisplatin resistance in melanoma.
There are contradictory reports on the relationship of IGF1R and acquired resistance in many human cancers. In NSCLC (Non-Small Cell Lung Cancer) cell lines, IGF1R activation could contribute to gefitinib resistance and give rise to the failure of the combination therapy [24, 25]. HCC (Hepatocellular Carcinoma) cells exhibited strong gefitinib resistance and the levels of phosphorylation in IGF1R and AKT were dramatically increased after drug treatment [26]. In advanced hepatocellular carcinoma, activation of IGF1R by ectopic down-regulation of miR-122 counteracted the effects of sorafenib-induced apoptosis, thus conferring sorafenib resistance [27]. MiR-143, miR-503 and miR-1271 modulated cisplatin resistance of human gastric cancer cells by targeting IGF1R [28-30]. These different results could be attributed to different cell contexts, experimental conditions, or assay approaches used in the various studies. In present study, as the target gene of miR-30a- 


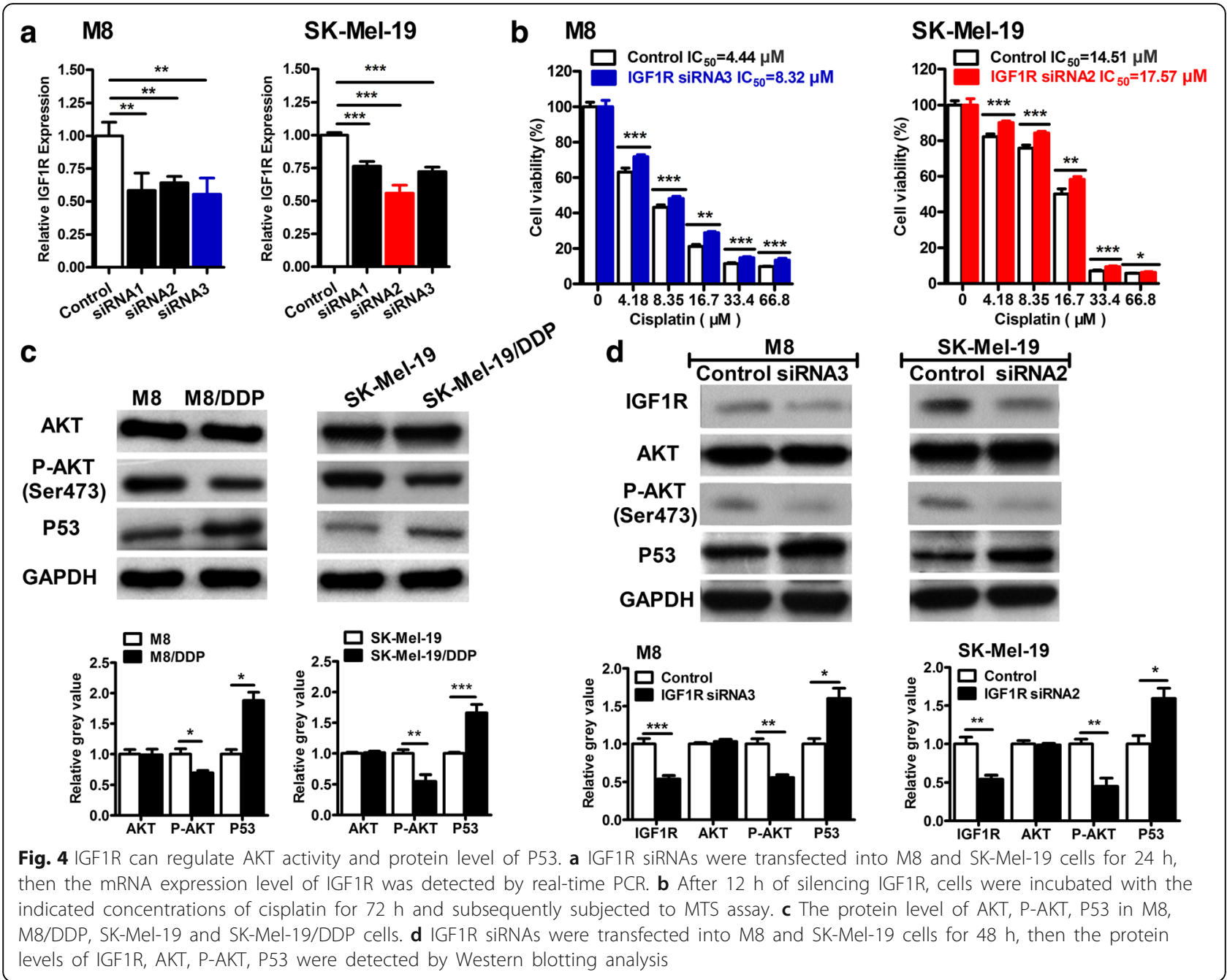

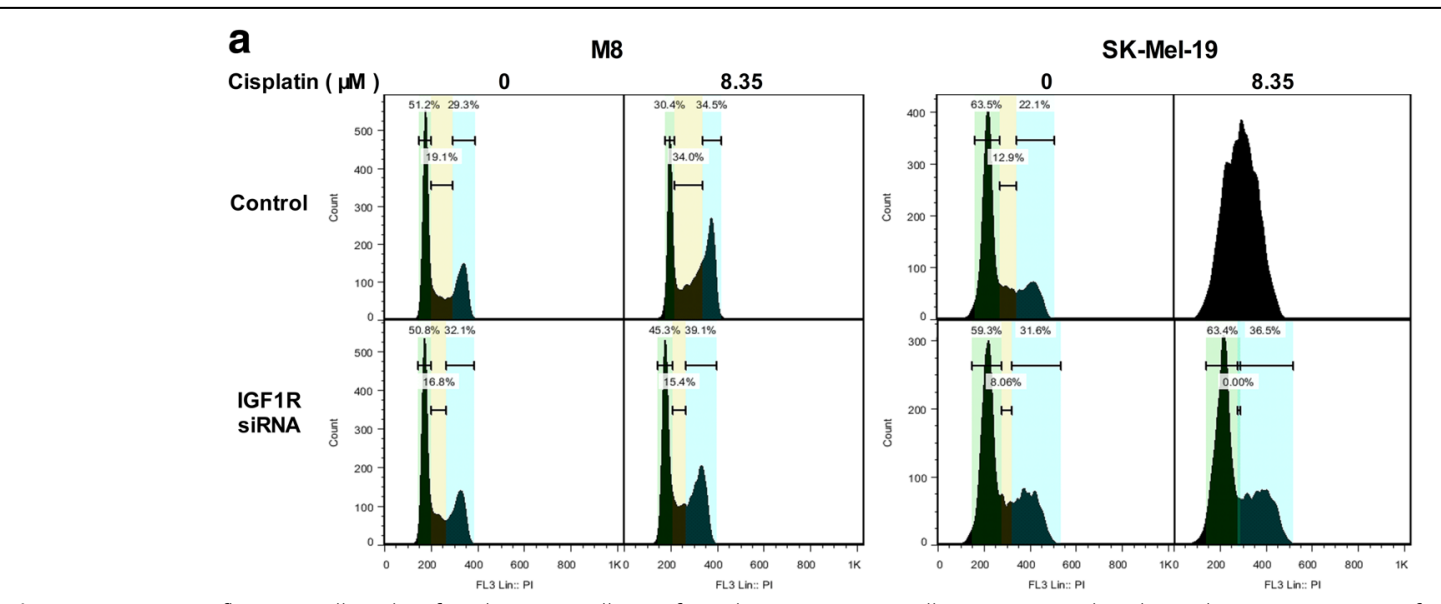

Fig. 5 IGF1R can influence cell cycle of melanoma cells. a After silencing IGF1R, cells were treated with cisplatin at $0,8.35 \mu \mathrm{M}$ for $24 \mathrm{~h}$, and the cell cycle of M8 and SK-Mel-19 cells was detected by flow cytometry 
$5 \mathrm{p}$, IGF1R is negatively correlated with cisplatin resistance.

IGF1R is a transmembrane receptor tyrosine kinase and can activate multiple downstream signaling cascades, among which the most prominent is the phosphatidylinositol 3 kinase/protein kinase B (PI3K/AKT) pathway [31-33]. PI3-kinase/AKT signaling can act on Mdm2 and thereby negatively regulate P53 [34]. In the present study, transfection of IGF1R-siRNA in M8 and SK-Mel-19 cells not only reduced the sensitivity to cisplatin but also altered the expression of phosphorylated AKT and P53, which subsequently induced cell cycle arrest in both cells. G2/M phase cell arrest here might serve as a protective mechanism following cisplatinDNA damage, avoiding replication of damaged DNA. And further investigation in other melanoma cell lines is necessary to explore the function and mechanisms of miR-30a-5p in cisplatin resistance of melanoma cells.

In the present study, we obtained these findings only in the cell models. The manifestation of resistance to cisplatin administration has not been related with molecular epidemiological data yet. Next we should concern the actual burden of this resistance mechanism to the human patient population. If there will be clinical trials, we may examine the expression of miR-30a-5p or IGF1R and form of P53 (mutant or wild type) in the patients with cisplatin resistance, and design potential targeted therapeutic approaches.

\section{Conclusion}

To summarize, our studies demonstrate that miR-30a-5p could influence cisplatin-resistance by targeting IGF1R gene and AKT/P53 pathway in melanoma cells, which might provide a potential target for the therapy of chemo-resistant melanoma cells.

\section{Abbreviations}

3'-UTR: 3' untranslated region; AKT: Serine-Threonine Protein Kinase; BSA: Bovine serum albumin; Ct: Threshold cycle; DDP: Cisplatin; DMEM: Dulbecco modified eagle medium; FBS: Fetal bovine serum; $\mathrm{IC}_{50}$ : The half maximal inhibitory concentration; IGF1R: Insulin Like Growth Factor 1 Receptor; JAG1: Jagged 1; Luc: Firefly luciferase; miRNA: microRNA; MTS: 3(4,5-dimethylthiazol-2-yl)-5-(3-carboxymethoxyphenyl)-2-(4-sulfophenyl)-2Htetrazolium; P53: Tumor Protein P53; PTEN: Phosphatase and tensin homolog; PVDF: Polyvinylidene fluoride; RI: Drug resistance indices; Rluc: Renilla luciferase; TuD: Tough Decoy; $\mu \mathrm{M}: \mu \mathrm{mol} / \mathrm{L}$

\section{Acknowledgements}

Not applicable.

\section{Funding}

This work was supported by Natural Science Foundation of Guangdong Province (Grant No.: 2015A030313754); Sanming Project of Shenzhen (Clinical Research Methodology team of Professor Yang Ke from Peking University Clinical Research Institute SZSM201612061; Oncological Chemoradiotherapy team of Academian Yu Jinming from Shandong Cancer Hospital SZSM201612041); Shenzhen Science and Technology Plan of Basic Research Projects (Grant No.: JCYJ20140416144209741, JCYJ20150403091443300, JCYJ20160427185121156,JCYJ20170306161757367).

\section{Availability of data and materials}

All data generated or analysed during this study are included in this published article [and its supplementary information files].

\section{Authors' contributions}

LYX did the most in-vitro experiments including cell culture, drug sensitivity assay, western blot analysis, plasmid construction, lentiviral infection and dual luciferase reporter assays. $Z J$ extracted the total RNA as well as the protein and did real-time quantitative PCR. $L Y J$ carried out the real-time PCR approaches. ZBY participated in real-time PCR analysis. ZFB participated in microRNA microarray analysis. WSB helped to draft the manuscript and participated in its design. $F Z Y$ conceived the study and draft the manuscript. All authors read and approved the final manuscript.

Ethics approval and consent to participate

Not applicable.

\section{Consent for publication}

Not applicable.

\section{Competing interests}

We declare that we have no financial and personal relationships with other people or organizations that can inappropriately influence our work. There are no professional or other personal interest of any nature or kind in any product, service and/or company that could be construed as influencing the position presented in, or the review of, the manuscript entitled, "MiR-30a-5p Confers Cisplatin Resistance by Regulating IGF1R Expression in Melanoma Cells".

\section{Publisher's Note}

Springer Nature remains neutral with regard to jurisdictional claims in published maps and institutional affiliations.

Received: 20 September 2017 Accepted: 15 March 2018 Published online: 11 April 2018

\section{References}

1. Kim SY, Yun SJ. Cutaneous Melanoma in Asians. Chonnam Med J. 2016; 52(3):185-93.

2. Willmes C, Kumar R, Becker JC, Fried I, Rachakonda PS, Poppe LM, Hesbacher S, Schadendorf D, Sucker A, Schrama D, et al. SERPINB1 expression is predictive for sensitivity and outcome of cisplatin-based chemotherapy in melanoma. Oncotarget. 2016;7(9):10117-32.

3. Bartel DP. MicroRNAs: target recognition and regulatory functions. Cell. 2009;136(2):215-33.

4. Dong $H$, Lei J, Ding L, Wen Y, Ju H, Zhang X. MicroRNA: function, detection, and bioanalysis. Chem Rev. 2013;113(8):6207-33.

5. Suzuki HI, Miyazono K. Emerging complexity of microRNA generation cascades. J Biochem. 2011;149(1):15-25.

6. Zhao JJ, Chu ZB, Hu Y, Lin J, Wang Z, Jiang M, Chen M, Wang X, Kang Y, Zhou Y, et al. Targeting the miR-221-222/PUMA/BAK/BAX pathway abrogates dexamethasone resistance in multiple myeloma. Cancer Res. 2015;75(20):4384-97.

7. Ma J, Fang B, Zeng F, Ma C, Pang H, Cheng L, Shi Y, Wang H, Yin B, Xia J, et al. Down-regulation of miR-223 reverses epithelial-mesenchymal transition in gemcitabine-resistant pancreatic cancer cells. Oncotarget. 2015; 6(3):1740-9.

8. Chen QY, Jiao DM, Wang J, Hu H, Tang X, Chen J, Mou H, Lu W. miR-206 regulates cisplatin resistance and EMT in human lung adenocarcinoma cells partly by targeting MET. Oncotarget. 2016;7(17):24510-26.

9. Zhou L, Qiu T, Xu J, Wang T, Wang J, Zhou X, Huang Z, Zhu W, Shu Y, Liu P. miR-135a/b modulate cisplatin resistance of human lung cancer cell line by targeting MCL1. Pathol Oncol Res. 2013;19(4):677-83.

10. Zhang Y, Duan G, Feng S. MicroRNA-301a modulates doxorubicin resistance in osteosarcoma cells by targeting AMP-activated protein kinase alpha 1. Biochem Biophys Res Commun. 2015;459(3):367-73.

11. Wang F, Li T, Zhang B, Li H, Wu Q, Yang L, Nie Y, Wu K, Shi Y, Fan D. MicroRNA-19a/b regulates multidrug resistance in human gastric cancer cells by targeting PTEN. Biochem Biophys Res Commun. 2013;434(3):688-94. 
12. Li Y, Li L, Guan Y, Liu X, Meng Q, Guo Q. MiR-92b regulates the cell growth, cisplatin chemosensitivity of A549 non small cell lung cancer cell line and target PTEN. Biochem Biophys Res Commun. 2013:440(4):604-10.

13. Shi L, Yin W, Zhang Z, Shi G. Down-regulation of miR-26b induces cisplatin resistance in nasopharyngeal carcinoma by repressing JAG1. FEBS Open Bio. 2016;6(12):1211-9.

14. Liu J, Tang Q, Li S, Yang X. Inhibition of HAX-1 by miR-125a reverses cisplatin resistance in laryngeal cancer stem cells. Oncotarget. 2016;7(52): $86446-56$

15. Shao XJ, Miao MH, Xue J, Xue J, Ji XQ, Zhu H. The down-regulation of MicroRNA-497 contributes to cell growth and cisplatin resistance through PI3K Akt pathway in osteosarcoma. Cell Physiol Biochem. 2015;36(5):2051-62.

16. Wang Z, Ting Z, Li Y, Chen G, Lu Y, Hao X. microRNA-199a is able to reverse cisplatin resistance in human ovarian cancer cells through the inhibition of mammalian target of rapamycin. Oncol Lett. 2013:6(3):789-94.

17. Haraguchi T, Ozaki Y, Iba H. Vectors expressing efficient RNA decoys achieve the long-term suppression of specific microRNA activity in mammalian cells. Nucleic Acids Res. 2009;37(6):e43.

18. Mc Clay EF, Mc Clay ME, Albright KD, Jones JA, Christen RD, Alcaraz J, Howell SB. Tamoxifen modulation of cisplatin resistance in patients with metastatic melanoma. A biologically important observation. Cancer. 1993; 72(6):1914-8.

19. Davol PA, Goulette FA, Frackelton AR Jr, Darnowski JW. Modulation of p53 expression by human recombinant interferon-alpha2a correlates with abrogation of cisplatin resistance in a human melanoma cell line. Cancer Res. 1996;56(11):2522-6.

20. Ge R, Liu L, Dai W, Zhang W, Yang Y, Wang H, Shi Q, Guo S, Yi X, Wang G, et al. Xeroderma Pigmentosum group a promotes autophagy to facilitate cisplatin resistance in melanoma cells through the activation of PARP1. J Invest Dermatol. 2016;136(6):1219-28.

21. Zhang $Y$, Yang $W Q$, Zhu $H$, Qian $Y Y$, Zhou L, Ren $Y$ J, Ren $X C$, Zhang L, Liu XP, Liu CG, et al. Regulation of autophagy by miR-30d impacts sensitivity of anaplastic thyroid carcinoma to cisplatin. Biochem Pharmacol. 2014;87(4):562-70.

22. Han X, Zhen S, Ye Z, Lu J, Wang L, Li P, Li J, Zheng X, Li H, Chen W, et al. A feedback loop between miR-30a/c-5p and DNMT1 mediates cisplatin resistance in ovarian Cancer cells. Cell Physiol Biochem. 2017;41(3):973-86.

23. Wang LL, Zhang $X H$, Zhang $X$, Chu JK. MiR-30a increases cisplatin sensitivity of gastric cancer cells through suppressing epithelial-to-mesenchymal transition (EMT). Eur Rev Med Pharmacol Sci. 2016;20(9):1733-9.

24. Ge X, Chen Q, Wu YP, Zhang Y, Xia H, Yuan D, Chen Q, Leng W, Chen L, Tang $Q$, et al. Induced IGF-1R activation contributes to gefitinib resistance following combined treatment with paclitaxel, cisplatin and gefitinib in A549 lung cancer cells. Oncol Rep. 2014;32(4):1401-8.

25. Peled N, Wynes MW, Ikeda N, Ohira T, Yoshida K, Qian J, llouze M, Brenner $R$, Kato $Y$, Mascaux C, et al. Insulin-like growth factor-1 receptor (IGF-1R) as a biomarker for resistance to the tyrosine kinase inhibitor gefitinib in nonsmall cell lung cancer. Cell Oncol. 2013;36(4):277-88.

26. Bodzin AS, Wei Z, Hurtt R, Gu T, Doria C. Gefitinib resistance in HCC mahlavu cells: upregulation of CD133 expression, activation of IGF-1R signaling pathway, and enhancement of IGF-1R nuclear translocation. J Cell Physiol. 2012;227(7):2947-52.

27. Xu Y, Huang J, Ma L, Shan J, Shen J, Yang Z, Liu L, Luo Y, Yao C, Qian C. MicroRNA-122 confers sorafenib resistance to hepatocellular carcinoma cells by targeting IGF-1R to regulate RAS/RAF/ERK signaling pathways. Cancer Lett. 2016;371(2):171-81.

28. Zhuang $M$, Shi Q, Zhang X, Ding Y, Shan L, Shan X, Qian J, Zhou X, Huang Z, Zhu W, et al. Involvement of miR-143 in cisplatin resistance of gastric cancer cells via targeting IGF1R and BCL2. Tumour Biol. 2015;36(4):2737-45.

29. Wang T, Ge G, Ding Y, Zhou X, Huang Z, Zhu W, Shu Y, Liu P. MiR-503 regulates cisplatin resistance of human gastric cancer cell lines by targeting IGF1R and BCL2. Chin Med J. 2014;127(12):2357-62.

30. Yang M, Shan X, Zhou X, Qiu T, Zhu W, Ding Y, Shu Y, Liu P. miR-1271 regulates cisplatin resistance of human gastric cancer cell lines by targeting IGF1R, IRS1, mTOR, and BCL2. Anti Cancer Agents Med Chem. 2014;14(6):884-91.

31. Wan X, Harkavy B, Shen N, Grohar P, Helman LJ. Rapamycin induces feedback activation of Akt signaling through an IGF-1R-dependent mechanism. Oncogene. 2007;26(13):1932-40

32. Davaadelger B, Duan L, Perez RE, Gitelis S, Maki CG. Crosstalk between the IGF-1R/AKT/mTORC1 pathway and the tumor suppressors p53 and p27 determines cisplatin sensitivity and limits the effectiveness of an IGF-1R pathway inhibitor. Oncotarget. 2016:7(19):27511-26.

33. Yamaguchi R, Harada H, Hirota K. VHL-deficient renal cancer cells gain resistance to mitochondria-activating apoptosis inducers by activating AKT through the IGF1R-PI3K pathway. Tumour Biol. 2016;37(10):13295-306.

34. Mayo LD, Donner DB. A phosphatidylinositol 3-kinase/Akt pathway promotes translocation of Mdm2 from the cytoplasm to the nucleus. Proc Natl Acad Sci U S A. 2001;98(20):11598-603.

\section{Submit your next manuscript to BioMed Central and we will help you at every step:}

- We accept pre-submission inquiries

- Our selector tool helps you to find the most relevant journal

- We provide round the clock customer support

- Convenient online submission

- Thorough peer review

- Inclusion in PubMed and all major indexing services

- Maximum visibility for your research

Submit your manuscript at www.biomedcentral.com/submit
C) Biomed Central 